VIAGENS DA LITERATURA CABO-VERDIANA ENTRE RAÍZES E RIZOMAS, ENTRE ÁRVORES E ONDAS: LITERATURA MUNDO PARA UMA PÁTRIA MUNDO

TRAVELS OF THE CABO-VERDIAN LITERATURE BETWEEN ROOTS AND RHIZOMES, AMONG TREES AND WAVES:

WORLD LITERATURE FOR A WORLD COUNTRY HOME

Simone Caputo Gomes 
Resumo: Chaves de leitura para a Poesia Cabo-verdiana contemporânea na sua relação com os conceitos de Literatura Mundial e Literatura-Mundo, com base em propostas teóricas de Zhang Longxi, David Damrosch, Armando Gnisci, Franco Moretti, Édouard Glissant, Helena Buescu e Zilá Bernd, entre outros pesquisadores. Constructos como transárea, arquipélago e vetorização, definidos por Ottmar Ette, bem como de Postpoesia, segundo Augustín Fernández Mallo, mostrar-se-ão também produtivos para o estudo da Poesia Cabo-verdiana.

Palavras-chave: Poesia Cabo-verdiana contemporânea; Literatura Mundial; Literatura-Mundo; Transárea; Postpoesia 
Abstract: Reading keys for Contemporary Cape Verdean Poetry in its relation to the concepts of World Literature and Littérature-Monde, based on theoretical proposals by Zhang Longxi, David Damrosch, Armando Gnisci, Franco Moretti, Édouard Glissant, Helena Buescu and Zilá Bernd, among other researchers. Constructs such as transarea, archipelago and vectorization, defined by Ottmar Ette as well as Postpoesia, according to Augustín Fernández Mallo, will also prove productive for the study of Cape Verdean Poetry.

Ketwords: Contemporary Cape Verdean Poetry; World Literature; Littérature-Monde; Transarea; Postpoesia 
With regard to world literature, we are all ignorant, for there is always something new and exciting for us to learn, always an ocean of undiscovered treasures lying before us while we stand on the seashore, holding just a few pebbles or shells in hand. (LONGXI, 2016, p. 122)

Na esteira das reflexões de Zhang Longxi em From Comparison to World Literature (2015), pretendo discutir a poesia contemporânea produzida por cabo-verdianos revisitando o conceito de literatura mundial de uma perspectiva planetária e buscando transcender o eurocentrismo ou qualquer outro etnocentrismo, já que, para o professor da Universidade de Hong Kong, "de Goethe e Marx a Casanova, Moretti e Damrosch, o conceito de literatura mundial foi teorizado principalmente no contexto de estudos literários ocidentais" (LONGXI, 2014, p. 521) ${ }^{1}$. Meu intuito é, descartando aqui a complexa discussão terminológica e teórica sobre os conceitos de literatura mundial e literatura-mundo, dar ênfase à tensão entre o local e o global, o nacional e o universal, que envolve questões fundamentais de comunicação transcultural, tendo em mente que "World Literature" é

\footnotetext{
1 "From Goethe and Marx to Casanova, Moretti, and Damrosch, the concept of world literature has been theorized mostly in the context of Western literary studies".
} 
"sempre um conceito que muda em resposta a necessidades e contextos locais" (LONGXI, 2014, p. 522) 2 .

Para o teórico dos estudos interculturais Leste-Oeste, a literatura mundial deve ser inclusiva, contemplando particularmente as tradições literárias que não foram bem estudadas além de seu ambiente nativo ou consideradas pertencentes a tradições literárias "menores". E esta linha de leitura deve ter em mente não apenas o nível qualitativo individual dos textos, "mas, num nível metatextual, observar padrões e trajetórias coletivos, formas [...] que contém a história da transformação de gêneros e temas literários" (LONGXI, 2017, p. 59).

Inicio, assim, minha intervenção com uma fala de Arménio Vieira, poeta detentor do Prémio Camões 2009, em entrevista à RTP (2014), lance primeiro de minhas reflexões sobre a Poesia Cabo-verdiana: "Quando era jovem, queria ser marinheiro, queria viajar. [...] Se você joga xadrez está aberto para tudo, se escreve poesia está no mundo" (VIEIRA, 2014).

Dialogando com o alemão Ottmar Ette e sua conferência denominada "Ciência da vida", proferida na Casa de Leitura Dirce Côrtes Riedel, no Rio de Janeiro (2017), compreendo "a Literatura como espaço onde se exercita a convivência Humana” (ETTE, 2017).

2 "World literature is thus always a concept that changes in response to local needs and contexts". 
Em sua obra $A$ sexagésima curvatura, Oswaldo Osório propõe, no poema "Signo Identitário": “Geográfica e sentimentalmente África e demograficamente e culturalmente mestiços não temos de ser europeus nem mais nem menos africanos. Temos, isso sim, é de saber conviver caboverdianamente neste vasto Atlântico que nos rodeia e a que desde cedo servimos de ponte de identidades" (OSÓRIO, 2007, p. 79, grifos meus).

Partindo dessas afirmações, como pensar a Literatura de pertença cabo-verdiana e, em especial, esta poesia na contemporaneidade, face a um mundo à deriva? $\mathrm{E}$ como se constrói essa pertença insular, arquipelágica, e ao mesmo tempo diaspórica, numa pátria erigida por elementos e fatores externos ao território desabitado encontrado em 1460 e colonizado por portugueses? Uma pátria-entre-mundos parece-me afinar-se com a ideia de uma escrita-entre-mundos, uma literatura viajante, de contato, de trocas, de movimento e devir, híbrida e pós-colonial, que possa interrogar paradigmas hegemônicos e transcender fronteiras e limites de ordem geográfica, genérica e temporal, como postulam Helena Buescu (2013, p. 36) e David Damrosch (2003, p. 496).

Com esse espírito, procurarei, de forma sucinta, apresentar um panorama de obras poéticas que, a princípio ainda mantendo laços com uma raiz de pertença, vão, em menor ou maior grau, ampliando a es- 
pacialização em vetorização, orientando-se para uma literatura mundial, quiçá "planetária" (SPIVAK, 2003, p. 72), desamarrada de uma raiz fundada no conceito de "nação" e presidida por uma concepção estrutural rizomática.

Costumo afirmar em meus escritos e aulas que a Literatura Cabo-verdiana nasce pela necessidade de mapear o espaço, de uma "fome de espaço" ou ânsia topográfica manifesta desde os relatos de viagens quinhentistas e seiscentistas de André Álvares d'Almada (1594, Tratado breve dos rios de Guiné do Cabo Verde) e André Do(r)nelha(s) (1625, Descrição da Serra Leoa e dos rios de Guiné do Cabo Verde), que misturam aspectos históricos, geoclimáticos, etnográficos e literários em textos genologicamente híbridos, mas que já demonstram que a apropriação da identidade cabo-verdiana pelo discurso literário se realiza primordialmente com fundamento na noção de espaço/ambiente, prestando-se a uma topoanálise (cf. GOMES, 2012, p 139).

São textos produzidos por uma elite local culta ${ }^{3}$, já que André Álvares d'Almada e André Do(r))nelha(s), considerados os primeiros literatos oriundos

${ }^{3}$ Como esclarece Almada (1994, p. 131), ele foi eleito pelo povo da (sua) ilha de Santiago para ir tratar com S. Majestade sobre se povoar a Serra Leoa, para onde os "moradores" do arquipélago se deslocariam, por melhores condições de vida e por estratégia comercial, o que lhe foi negado, diante da intenção da Coroa de manter a posição estratégica das ilhas de Cabo Verde no globo. E André Do(r))nelha(s) integrou a armada portuguesa envolvida em batalha com os franceses na Serra Leoa, em 1574, escrevendo seu texto-descrição somente em 1625. 
das ilhas de Cabo Verde, eram viajantes, "habituados a longo e intenso trato com múltiplas e variadas populações africanas", como afirma Teixeira da Mota (1971, p. 7). O período de 1574 a 1625, que compreende as suas obras, "foi decisivo na história da África Ocidental, nomeadamente do arquipélago de Cabo Verde" (MOTA, 1971, p. 6).

0 painel da Literatura Cabo-verdiana que ora traço parte, portanto, do local, mas já com vocação continental; estende-se ao regional, nacional e transnacional: o canto de "Nha Terra" Cabo Verde foca, desde os relatos quinhentistas e seiscentistas, passando pelos poemas nativistas do século XIX, a ilha natal como representação simbólica das dez ilhas. Estende-se ao arquipélago com o claridoso Jorge Barbosa (século XX) e segue seu caminho rumo ao mundo, como pretendo demonstrar. A vocação migratória e transnacional assoma desde a literatura de viagens, que demonstra o desejo dos habitantes da ilha de Santiago de alcançar e povoar a Serra Leoa, na chamada costa da Guiné, como documenta o cabo-verdiano André Álvares d'Almada, em obra classificada nas bibliotecas especializadas ora como cartografia, ora como geografia, ora como etnografia, ora como literatura (FERREIRA, 1977, p. 13) e, segundo Teixeira da Mota, "o mais antigo testemunho da vocação migratória do caboverdeano” (MOTA, 1971, p. 6). 
Correlato ao desejo pelas amenidades da abundante e fresca Serra Leoa, o trauma das fomes de seu tempo (especialmente a de 1583, em Santiago), com carga dramática, já é representado por André Do(r) nelha(s), que refere no Cap. 1 de sua obra a abundância das águas das ribeiras, poças e noras daquela Serra face às secas do arquipélago cabo-verdiano.

Assim, na reflexão de José da Silva Horta (2005, p. 1-14), representações mestiças já pontuavam os textos dos dois cabo-verdianos citados e a apropriação do espaço pelas práticas discursivas relacionava-o estreitamente às práticas mercantis políticas ou religiosas ou às projeções (como a colonização da Serra Leoa por cabo-verdianos, à época proibida pelo colonizador) dos habitantes de um arquipélago já assolado pelas secas: "os mecanismos metafóricos e metonímicos que estão na base da produção do espaço ganham um significado profundo" (HORTA, 2005, p. 13):

Remexendo mais peças do tabuleiro e avançando a reflexões de Ottmar Ette sobre o saber da convivência em Worldwide: Archipels de la mondialisation (2012), lembro que: "las islas y los archipiélagos, vistos en diferentes niveles, jamás han de ser entendidos como figuras ancladas en un sitio fijo, sino como entidades dinámicas." Desta forma, a "estrutura significativa da ilha é pelo menos dupla. Por um lado, pode significar um estado fechado, isolado do Outro; 
por outro, a consciência de uma relacionalidade de múltiplas formas com o Outro" (ETTE, 2005: 136).

Tendo em mente os deslocamentos que orientam a Literatura Cabo-verdiana do que chamo uma história do espaço para uma poética do movimento, observemos ainda algumas passagens que tentam definir uma raiz ou pertença ao discurso, mas já apontam para esta perspectiva dupla.

A metáfora do "pássaro fechado" (Obra poética, p. 329), que julgo presidir a poética de Jorge Barbosa, sobretudo nos antológicos poemas do ciclo "Meio milênio" (num balanço de "5 séculos de abandono e retardado progresso", p. 381) e na epopeia sumária "Expectativa" (mormente no Canto 4o, em que a ilha é "redondo espaço aflitivo" (p. 180), "desesperado cenário" (p. 186 ) que "comprime”, "reduz" e "desespera" (p. 180), é ladeada por uma "estampa [...]/com o retrato de um menino/que tinha à sua frente/uma grande esfera giratória/como mapa-múndi assinalado", p.174-175). E a partir daí, declara o poema: "o poeta imaginou/um lento impulso/nos dedos finos do menino/rodando assim o globo/inclinado sobre o eixo/ varado em diagonal...//Da rotação surgiram/na visão do poeta/surgiram e passaram/com as suas cores/ variadas e cintilantes/nações e continentes" (p. 175).

0 enfoque propõe uma abertura, de um mundo fechado ao infinito, e a entidade "ilha" pode ser com- 
preendida, por um lado, como ilha-mundo, dentro da qual uma totalidade se espacializa, e, por outro lado, como ilha-para-o-mundo, com múltiplas possibilidades de conexão, seguindo o rastro do pensamento de Ottmar Ette.

Vera Duarte, apropriando-se da imagem do pássaro fechado no século XX e aliando-a ao pathos da poética de Florbela Espanca, representa a trajetória de um eu lírico feminino expansível aos sujeitos femininos de todo o mundo em seu [0] arquipélago da paixão (2001). Do primeiro caderno -“Na impossibilidade do amor" - e na mais desamparada solidão em que se debate ("ai pobre de mim traída/ ai pobre de mim deixada [...] ai pobre de mim deixada/ ai pobre de mim traída"), o sujeito feminino representado percorre caminhos de libertação que culminam no êxtase da realização amorosa, "corpo insurrecto" (p. 47) que se libertou da dor, no caderno 2 :

Ter-te-ei alguma vez dito homem de tormentas mil e desassossegos vários que tu és o meu homem [...] Quando em êxtase cavalgo pelas estepes agrestes do teu corpo perfeito - bô ê nha ôme [...] Tu és guiné 
e és berlim

tu és praia

e és salamansa

tu és Nicarágua

e és mi hombre

Quero ter-te em paixão

com sabor do maracujá

que me enlouquece os sentidos

[...]

Teu corpo é corpo de homem

onde desagua meu rio de mulher

Tu est mon homme [...]

Du bist mein man,

You are my man,

Bô ê nha ómi

Bô ê nha ómi (DUARTE, 2001, p. 68-73).

Redimensionando a história do amor-sofrimento relegado às mulheres por estruturas hegemônicas milenares de dominação patriarcal, dedicando poemas a várias escravas humilhadas e a grandes redentoras reais ou mitológicas de uma história das mulheres (como Antígona, Safo e a Rainha Ginga), Vera expressa a abertura para o voo do pássaro, em estrutura translingual e polipoética em que ecoam, além de Jorge Barbosa e Florbela, as vozes de Sófocles, John Keats, Rimbaud, Gil Vicente, Manuel Alegre, Mário de Andrade, Arnaldo França, Dina Salústio, Manuel Lopes, Mário Fonseca, Osvaldo Alcântara, Oswaldo 
Osório. A poesia rompe as fronteiras da ilha-isola e o faz em textos-viáticos prosapoéticos, recheados do hibridismo genológico tão caro à poesia contemporânea, que busca transpor também as fronteiras discursivas.

No seu caminhar, a par de uma cabo-verdianidade que se expressa com ênfase e como raiz em obras como Poemas de longe, de António Nunes (1945), Terra gritante, de Luis Tolentino (s.d., de 1971-1975), Canto a Cabo Verde (1988), de David Hopffer Almada (e muitas outras obras poderiam ser citadas), ora sob o signo do desalento, ora do princípio esperança, a Literatura Cabo-verdiana nos apresenta textos que se lançam para o mundo, mimetizando, ou melhor, transfigurando, sua experiência diaspórica:

[...] daqui zarparam naus e veleiros, braços de pedra, arpoadores de cetáceos, ondas gigantes, gentes remotas, filhos do fogo, dez ilhas secas, sede sem fim... Xango, Uatanka, Cristo, Schalom, sou negro, índio, lusitano, hebreu, marinheiro das ilhas, num norte sul, cheiro a goiaba, delicioso carpo, orgasmo forte, fruto colonial, carrego em mim continentes e mundos (FIGUEIRA, 2012, p. 18).

Glissant, em entrevista reproduzida em Pour une littérature-monde, declara: 
Acredito ter sempre obedecido a um instinto que me levava primeiramente a considerar que o objeto mais alto da poesia era o mundo: o mundo em devir, o mundo que mexe conosco, o mundo em sua obscuridade, [...] lugar de encontros, de choque das culturas, das humanidades (2007, p. 78).

José Luís Hopffer Almada, nos seus Sonhos caminhantes (2017), reúne périplos de cabo-verdianidade e aventuras de heteronímia poética, trazendo à luz movimentos centrífugos e centrípetos da identidade e da poesia cabo-verdianas:

Saídos das ilhas vulcânicas, cabo-verdianos pululam nas ruas de Nova York S. Paulo e Pequim laboram nos portos de Roterdão Dakar e Nanquim suam nos andaimes de Lisboa Luanda e Berlim ("Não há dia, não há manhã", poema do heterônimo Nzé de Sant'y Ago, p. 107).

A estrutura relacional arquipelágica concebida, para além da geografia, como um modo de estar no mundo, transforma o indivíduo crioulo em ilhas, plural que envolve as dez ilhas e ainda a diáspora, denominada de décima primeira ilha (e que abriga, hoje, o maior número de cabo-verdianos): 
Assim, a pluralidade, acrescida de uma flexibilidade necessária ao modo de 'estar-entre', é traço fundamental à vivência cabo-verdiana e o autor opta por expressar-se por meio de uma aventura heteronímica que abriga faces poéticas possíveis de veicular ao leitor a riqueza de experiências de enraizamento e deslocamento pertinentes a essa aventura crioula de mobilidade e plasticidade (GOMES, 2017, p. 156).

Conjugados, nomadismo e heteronímia falam de um mundo que já não comporta identidades fixas, nacionais, culturais, políticas e mesmo individuais, criando-se formas de expressar a complexificação da sociedade. A imagem de nação, à luz das concepções teóricas atuais, é carregada de complexidade, ainda mais no caso de Cabo Verde, cuja constituição transcultural e híbrida, somada a aspectos arquipelágicos e diaspóricos, exige cuidados especiais na discussão do conceito de cabo-verdianidade.

Identidade, hoje, segundo Hans Ulrich Gumbrecht, é uma categoria teórica que engloba inúmeros processos de superposição (GUMBRECHT, 1999, p. 115); se tomada apenas como identidade nacional (conceito utilizado como base para fundamentar as histórias das literaturas dominantes no século XIX), corre-se o risco de "minimizar identidades" (GUMBRECHT, 1999, p 115-124) e de perder-se a flexibilidade ne- 
cessária à investigação de uma cultura em movimento constante e mutante, como a cabo-verdiana, caracterizada pelo fenômeno do "terra-longismo" proposto por Manuel Ferreira (1972), de partidas e regressos, mútuos e frutuosos intercâmbios decorrentes, em grande parte, da vivência diaspórica, que sempre caracterizou Cabo Verde (desde a nascença) como nação-para-o-mundo.

Mas caminhemos um pouco mais, buscando outras peças para tornar mais instigante este jogo de xadrez.

A princípio, a poética de Corsino Fortes funda-se numa épica de raiz utópica (a construção do país) e estrutura arborescente na trilogia $A$ cabeça calva de Deus (2001), em que acompanha e se faz arauto da gesta da colônia que fabrica sua independência (Pão \& fonema), do povo que festeja sua hora zero (Árvore \& Tambor) e da consolidação das estruturas que constroem o país na pós-independência (Pedras de sol \& substância). Contudo, seu derradeiro livro, Sinos de silêncio (2016), cujos poemas líricos foram primeiramente publicados de forma esparsa no Facebook, demonstra preocupação existencial e ontológica e alarga os horizontes da reflexão metapoética de diálogos ocidentais (com Pablo Neruda, Ezra Pound, Saint-John Perse, Maiakovsky, Rimbaud, João Cabral de Melo Neto) a convivências transespaciais 
e transtemporais com o Oriente (representado por Bashô e pela forma "haiku", adotada para a maioria dos textos).

O conceito de "transárea", postulado por Ottmar Ette (2016), que já subjazia a obra fundacional da cabo-verdianidade - pois no "sangue das palavras" do poeta Corsino já se traçavam "pistas para óvnis" (2001, p. 123) e a ilha-ovo do mundo-útero-África apontava seu "úbere" para a "Via Láctea" (p. 130) -, apresenta-se nitidamente no derradeiro livro:

ZEN
Sapo de Bashô
Salta \& mergulha no aquário
Da minha ... insónia
(FORTES, 2016, p. 91)

Pelo exposto, depreende-se que os conceitos de Literatura mundial e de Literatura-mundo, a par das discussões teóricas que envolvem, podem ser eficazes para a leitura de obras que estabelecem um profundo diálogo com textos literários de outras latitudes. Em What Is World Literature? (2003), David Damrosch defende que as questões suscitadas pela World Literature têm sobretudo que ver com a circulação e a recepção dos textos literários, que deixam de estar confinadas a um espaço ou uma língua. Para o norte-americano, a World Literature engloba todos 
os textos que circulam para lá da sua cultura de origem, seja em tradução, seja na sua língua original.

Refratando-se de uma concepção do literário exclusivamente centrada na ideia de nação, o conceito de "literatura-mundo", segundo Helena Buescu, destaca a possibilidade de conceber diferentes mapas da produção literária, relativizando a existência de uma hierarquia pré-fixa e sublinhando um movimento de natureza mais rizomática" (2013, p. 48). Para Zilá Bernd:

Face à extrema mobilidade territorial e cultural na contemporaneidade, aos deslocamentos e migrações que se realizam de um território ao outro, mas também no interior de um mesmo país ou de uma mesma cultura [...], classificar as literaturas pela pertença a uma única nação tornou-se não apenas complicado, como cada vez mais irrelevante (2018, p. 1).

Jorge Carlos Fonseca, em seu híbrido texto $O$ albergue espanhol (2017), que põe sob suspeita a forma canônica do romance inundando-a de metacrítica e, sobretudo, de poesia, afirma, pela voz do narrador: "Aliás, o romance-poema-manifesto em causa bem poderia ser escrito por natural de uma qualquer outra cidade ou de outro mundo, já que não contém 
marca nenhuma de autenticidade da 'cidade real' " (FONSECA, 2017, p. 200).

Tornando-se mais complexa a noção de pertença identitária, a ideia de errância leva os poetas a ensaiar outros acessos ao conhecimento do mundo. Bernd (2018, p. 8) complementa:

O que se vê cada vez mais em diferentes literaturas são processos de hibridação múltiplos. Isto dá origem ao nascimento de uma littérature monde (globalizada, mas no bom sentido, com eliminação de fronteiras culturais, com escritores de diferentes etnias que elegeram livremente seus "modelos" ou "ancestrais" em autores de abrangência universal).

Os cabo-verdianos Corsino Fortes, Filinto Elísio e Arménio Vieira, por exemplo, assumem a vocação global da identidade plural cabo-verdiana numa interlocução não somente com obras em língua portuguesa, mas com obras ocidentais e orientais, rumo a uma literatura global (especialmente no caso deste último), que exige leitura e recepção transversais e memória literária para dar conta da circulação de textos alheios nos poemas.

Entre raiz e rizoma ou entre "árvore e onda" (metáforas utilizadas por MORETTI, 2000, p. 181) move-se a obra poética de Filinto Elísio. Em entrevista a 
mim concedida em maio de 2017 (p. 222), define o poeta: "Já disse algures que sou universal, um cabo-verdiano que, pelo seu sentir humanista, posiciona-se como cidadão do mundo. Sou ilha e cosmos".

O poema, na lavra de Filinto Elísio, é frequência energética, poema em processo, em sintonia com os conceitos de energia $\mathrm{U}^{4}$ (vide Me_xendo no baú. Vasculhando o $U$ ), interatividade e transdisciplinaridade. Como Jean Tinguely, escultor suíço e engenheiro que introduziu a arte cinética durante a exposição Le Mouvement, 1955, em Paris, buscando libertar a escultura de uma condição estática, Filinto busca imprimir à expressão literária energias potenciais associadas a mútuas e múltiplas interações.

As relações intra e intertextuais e as interações com o leitor tendem ao máximo de entropia, em função crescente face à quantidade de informação do sistema-texto e às mudanças flutuantes da matéria poética. A abertura à participação ativa do leitor na construção de sentidos e o rompimento de paradigmas, que contraria os hábitos interpretativos do usuário dos códigos poético e linguístico, sugerem o caminho da leitura rizomática da obra, sob o signo da viagem, odisseia existencial ou poética. 0 nomadismo ou trânsito e o não estabelecimento de identida-

${ }^{4}$ Conceito que une as energias cinética e potencial de um sistema. 
des fixas funcionam como oposição à hierarquização de instituições tradicionais.

Tal arquitetura permite compreender o conceito de vetorização proposto por Ette (2016, p. 192 et passim) para a literatura, ou seja, a possibilidade de atravessamento do espaço, com limites esfumados. No poema "Mareações em viagem", de Zen limites, propõe o poeta: "Não descortino fronteiras para a viagem/ do poema” (ELÍSIO, 2016, p. 81).

A antropofagia de textos e de mundos pelos quais o Ulisses lírico filintiano deambula (confira-se os títulos gerundivos - "mexendo", "vasculhando" - e progressivos - "quase" - dos livros mais recentes) perpassa uma geografia que se estende dos destroços da Atlântida, por ilhas e continentes, espaços vulcânicos e cósmicos, expandindo-se aos quatro elementos: água, terra, fogo e vento (ar):

\section{El Paseo}

Poetar É marear, circum-navegando - qual Ulisses, deambular os mares gregos, assim D. Quixote em rodeio pela Mancha e a mãe de Macunaíma, largando a cevadeira, levá-lo a passear no mato (ELÍSIO, 2016, p. 31).

A escrita estabelece transgressões nas texturas e caos no(s) cosmos, arquiteta labirintos com caminhos de prosa e verso (ou de quase prosa / qua- 
se verso) que o leitor percorrerá, qual Teseu, com o auxílio de fios de Ariadne, para experienciar estados excessivos (desvarios, ardores, êxtases, grandes amores, metáforas viscerais, paroxismos, pressa das cidades) expressos por uma linguagem rica em antíteses, transmutações e neologismos.

0 reino de Baco - com seu arrebatamento, prazeres etílicos, humor, ludismo e subversão da ordem - impera nos textos de Filinto, desde os títulos dos livros (Li Cores \& Ad Vinhos; Me_xendo no baú. Vasculhando o U; ZEN limites) à diversidade de gêneros, assuntos e tons que habitam a tecedura textual. Mexer no baú para vasculhar e "desoficinar a poesia" é uma das mais importantes mensagens da obra de Filinto Elísio. "Re-mexer" é um renascer a cada poema. E re-mexer com ciência e consciência da poesia, já que o escritor explicita em sua obra a vasta cultura literária adquirida. "Remoer livros" é um hábito deste poeta-leitor contumaz. A voracidade, da vida e da leitura, constitui o brasão do escudo da linhagem filintiana:

\footnotetext{
Navegações

Apesar do tempo, amofinado para se ler toda a poesia escrita (o grande patrimônio) imaterial e espiritual, sempre é possível roubar horas diante de Fernando Pessoa. Quando não percorrer os versos de Omar Khayam, de Leopold Sedar Sengor ou de Jorge Luis Borges. Se prosa, a não
} 
prosaica, passe a expressão, mas poética, deixem-me com as linhas de Guimarães Rosa, de James Joyce e de José Saramago. Olho para minha estante de livros e está aí o perfeito concubinato entre Carlos Drummond de Andrade e Charles Baudelaire, bem como a cumplicidade com que Corsino Fortes vai para a leitura de Umberto Eco. Captain, Oh Captain... terei eu tempo, caro Walt Whitman, de navegar em todos os poemas de Rabindranath Tagore? (ELÍSIO, 2016, p. 108)./

Totalmente inserido na contemporaneidade, Filinto Elísio viaja por idioletos literários mundiais, vasculhando letras, cifras, signos, sinais hieroglíficos, ideogramas, grafites, pinturas, tatuando o corpo da poesia com um alfabeto ulterior $(\mathrm{U})$, que vagueia no tempo entre o alfa ("escritos cirílicos") e o ômega $(\Omega)$ dos weblogs, twitters, facebooks, terabytes, underlines e underscores. A experimentação a partir de artefatos poéticos que fluem em vetores multiplamente orientados afina sua produção com o que o escritor espanhol Agustín Fernández Mallo (2009, p. 28) denomina de "postpoesia" ("poesia expandida" ou um "novo paradigma" para a poesia), que intenta sacudir o museu da poesia ortodoxa (MALLO, p. 12) ao fazê-la conviver com outras artes e saberes, incluindo os digitais, e ao trabalhar com zonas de fronteira, híbri- 
das, buscando outros caminhos para a expressão de forma crítica e isentando-se de posturas utópicas.

Como proposta por Alain Mabanckou (congolês residente na Califórnia), “a literatura-mundo é aquela que funda cumplicidades para além dos continentes, das nacionalidades, dos catequismos e das árvores genealógicas" (2007, p. 61) e essas cumplicidades se estendem entre artistas que se comunicam, entre leitores e escritores, entre tempos e formas, criando redes, movimentando-se e misturando-se.

A produção de Arménio Vieira, no que concerne às cumplicidades poéticas, figura-se-me como exemplar e nisto concordo novamente com Zhang Longxi, quando afirma que é necessário, para a literatura mundial, propor "argumentos críticos que convençam leitores porque uma obra em particular é valiosa para uma escala global" (2017, p. 63). Arménio é o que chamo poeta-leitor, que dá a medida do que leu e bem metaforiza esta artimanha literária no poema "Canto das Graças", em que vozes e textos planetários são evocados, pontificando Borges, metáfora do Grande Leitor:

Para Jorge Luis Borges, de quem herdei o mote, se é que ainda pode ler quem já tudo leu (VIEIRA, 2016, p. 50) 
Por sua vez, o eu lírico armeniano declara:

Li-os todos. Pela mão de Homero [...] vi a morte de quem sabia que o Grego era o braço do Destino, bem mais forte do que a espada. Li-os todos, e pela mão de Dante desci aos Infernos [...]. Com Milton não quis entrar no Paraíso [...]. Com Whitman soube o que era um bardo (VIEIRA, 2009, p. 15).

A tendência à indagação ontológica da vida se alia à indagação das questões e limites da poesia, com exacerbação da erudição estética, do uso dos artifícios da intertextualidade, da intermidialidade e da releitura. A obra de Arménio Vieira é paradigmática desta vertente poética que exige um leitor iniciado e erudito. Uma poética rizomática, associada a uma visão poliédrica de postpoesia derivada de um “comportamento lúdico-construtivo" (MALLO, 2009, p. 99) ultrapassa uma cabo-verdianidade tribalcêntrica (p. 162) de raiz social e política e assume uma pluralidade "opuscêntrica" (p. 162), complexa, heterogênea estética e culturalmente, evidenciando um planetarismo poético e a afinidade com o conceito de literatura mundial, especialmente a partir da obra MITOgrafias.

A poesia de Arménio Vieira supõe uma rede aberta de interações possíveis a partir de um atrator caó- 
tico (MALLO, 2009, p. 171) que enreda o leitor numa teia de janelas ou platôs deleuzianos que se abrem simultaneamente em hipertexto com inúmeras entradas e linhas de fuga, como é possível observar na estrutura do seu texto No inferno, que ganha merecidamente caminhos internacionais, e no qual revisita os infernos literários sob o signo da Biblioteca de Babel borgiana.

Como algures declarei, o poeta "explicita o destino de sua viagem poética: 'navego rumo ao país onde nasceram os grandes poemas, e, enlouquecendo, assumo o árduo ofício de os escrever, depois de os ter queimado' (2009, p. 50). Tal como no bailado de Tchaikovsky, 'morrendo o cisne, renasce a fênix' " (GOMES, 2011, p. 53). Revisitar criticamente o cânone ocidental, rasurá-lo, parece ser o móvel do escritor.

Refletindo sobre a contemporaneidade, a reflexão de Armando Gnisci (2010, p. 31) corrobora minha leitura:

O nosso século pode ser intitulado "sistema-mundo", segundo o sociólogo americano Immanuel Wallerstein; uma época em que o universalismo europeu, de descendência goethiana, chegou ao fim. 0 que nos cabe fazer, literatos e leitores do século XXI, mas de uma geração nascida e formada no século XX? Por um lado, há que aceitar respeitosamente essa hereditariedade europeia, por outro, há que transmiti-la criticamente, a contrapelo, como 
sugeriu Benjamim, e revisitá-la de modo absolutamente crítico".

É este movimento que verifico na análise da obra poética de Arménio Vieira:

Apaga as escrituras. [...] Em ti há um marinheiro demandando uma ilha onde ninguém ainda esteve. Também em ti encontrarás o mapa, a bússola e o navio. Há coisas a que não deves atribuir nomes. A tua ilha não tem nome (2009, p. 11).

O destino dos poemas é uma ilha outra, para além das ilhas cabo-verdianas. Abre-se para o mundo. 0 próprio poeta refere sua profunda interação com um repertório literário enciclopédico antropofagicamente deglutido e, pela astúcia da mímesis, devolvido ao seu leitor, de forma criativa inusitada e prismática:

$\mathrm{Eu}$, que de Homero recebi o poema no instante em que o poema nasce, e vi o Inferno pela mão de Dante, tal-qual Leopardi mais tarde o viu, e, após me afundar no rio onde Hamlet e Lear beberam o vinho que enlouquece, comecei a ter visões que Rimbaud, De Quincey e Poe registaram em negros textos; eu, que no eterno transportei a bandeira que era peso nas mãos de Elliot, e renovei a char- 
rua com que Pound lavrava os versos, e de Whitman furtei-me ao licor, que em Álvaro, digo Campos, porque dorido e menos doce, sabia melhor; então que falta em mim para de Camões herdar a estrela, que Pessoa deixou fugir? (poema “Megalomania", 2009, p. 48).

Na linha do conceito de polinização e não de influência (de uma literatura nacional sobre outra) podemos ler esses textos que evidenciam que a mundialização da literatura deve ser valorizada, como quer Armando Gnisci, "enquanto conquista de pendor pós-colonial efetuada por muitos escritores latino-americanos, africanos, caribenhos, asiáticos e australianos, para além dos europeus e dos norte-americanos", consistindo numa "mundialização das mentes" (GNISCI, 2010, p. 28-31).

Essa polinização ou estrutura rizomática da poética armeniana, que dialoga com uma multiplicidade de textos canônicos ou não e em que há uma indecidibilidade sobre "onde bifurca a prosa e, nítido,/ se vê o poema” (2016, p. 60), acaba frequentemente por se expressar como jogo, na sua acepção de alteridade e movimento ("O jogo é a realização do movimento como tal", afirma Gadamer, 2005, p. 156-157). 0 poema a seguir tematiza esta estratégia:

As palavras com que se tece um poema lembram as bolas de um jogo de bilhar. E elas 
carambolam, se esquivando, se juntando. E dançam, como se fossem bailarinas, seguindo os passos de quem segura o taco e nele encontra sua vara de condão. É o que parece, mas não é, porquanto no interior das palavras mora uma gazela insubmissa, a que o poeta se rende e presta culto, inda mais que um amante se entregando aos caprichos da grande sedutora (VIEIRA, 2013, p. 27).

Para finalizar, ainda tendo muito por dizer, volto ao ponto inicial de minha viagem labiríntica citando três poetas do mundo e para o mundo:

Arménio Vieira: "Se você joga xadrez está aberto para tudo, se escreve poesia está no mundo".

Filinto Elísio:

0 poeta, na sua individualidade, escreve para a sociedade universal, para a Humanidade. Entre todos os falares com que a sociedade universal revela o seu pulsar e sua intenção, presumo ser a fala poética aquela que agrega melhor seus valores e apelos (2009, epílogo).

Mário Fonseca:

Para um canto verdadeiramente Humano

Antepassados imortais imortal Maiakovsky 


imortal Rimbaud
imortal Camões
imortal Keats
imortal Eluard
imortal Lorca
imortal Whitman
e vós outros
inumeradas gargantas

de onde brotam

flamejantes dardos

da consciência humana [conclamo-vos]

em assembleia

plenária

aberta

a todos os gritos

a todos os ventos

a todos os sonhos

de todos os homens (1998, p. 85)

\section{Referências}

ALMADA, André Álvares d'. Tratado breve dos rios de Guiné do Cabo Verde. Introdução, modernização do texto e notas de António Luís Ferronha. 1. ed. Lisboa: Grupo de Trabalho do Ministério da Educação para as Comemorações dos Descobrimentos Portugueses, 1994. ALMADA, David Hopffer. Canto a Cabo Verde. Praia: Instituto Cabo-verdiano do Livro, 1988. 
ALMADA, José Luís Hopffer. Sonhos caminhantes. Praia: Pedro Cardoso Livraria, 2017. Posfácio Simone Caputo Gomes.

BARBOSA, Jorge. Obra poética. Lisboa: Imprensa Nacional-Casa da Moeda, 2002.

BERND, Zilá. Colocando em xeque o conceito de literatura nacional (2007). Disponível em: <http://www. zilabernd.com/pdf/UFF2007.pdf>. Acesso em 12 de abril de 2019.

BUESCU, Helena. Experiência do incomum e boa vizinhança: Literatura Comparada e Literatura-Mundo. Porto: Porto Ed., 2013.

DAMROSCH, David. What is World Literature? Princeton: Princeton University Press, 2003.

DO(R)NELHA(S), André. Descrição da Serra Leoa e dos rios de Guiné do Cabo Verde, 1625. Introdução, notas e apêndices por Avelino Teixeira da Mota. Lisboa: Junta de Investigações Científicas do Ultramar, 1977. DUARTE, Vera. $O$ arquipélago da paixão. Mindelo: ARTILETRA, 2001.

ELÍSIO, Filinto. Li Cores \& Ad Vinhos. Lisboa: Letras Várias, 2009.

ELÍSIO, Filinto. "Retratos". Jornal A SEMANA, Praia, 23 de maio de 2009.

ELÍSIO, Filinto. Me_xendo no baú. Vasculhando o U. Lisboa: Letras Várias, 2011.

ELÍSIO, Filinto. Zen limites. Lisboa: Rosa de Porcelana, 2016. 
ETTE, Ottmar. Von Inseln, Grenzen und Vektoren: Versuch über die fraktale Inselwelt der Karibik. In: BRAIG, Marianne/.ETTE, Ottmar/ INGENSCHAY Dieter/ MAIHOLD, Günther; (ed.): Grenzen der Macht - Macht der Grenzen. Lateinamerika im globalen Kontext. Frankfurt M.: Vervuert Verlag, 2005, p. 135-180. ETTE; Ottmar; Müller; Gesine (eds.). Worldwide: Archipels de la mondialisation. Archipiélagos de la globalización: contribuciones en español, francés, inglés y alemán. (Spanish Edition). Madrid: Iberoamericana Editorial Vervuert, 2012.

ETTE; Ottmar. Pensar o futuro: a poética do movimento nos Estudos de Transárea. Rio de Janeiro, ALEA, v. 18/2, p. 192-209, mai-ago. 2016.

ETTE. Ottmar. Ciência da vida. Conferência em 3 partes. Rio de Janeiro: Casa de Leitura Dirce Côrtes Riedel, 4 de dezembro de 2017. Disponível em:

<https://www.youtube.com/watch?v=74F6L4JvNbM\&list=PLZugpfRLjZ_qb9xNc8ApP35kT2vd-3Sn1>; <https://www.youtube.com/watch?v=nWoJICmV0zg\&list=PLZugpfRLjZ_qb9xNc8ApP35kT2vd-3Sn1\&index=2>; <https://www.youtube.com/watch?v=3FV6dTKLV1U\&index=3\&list=PLZugpfRLjZ_qb9xNc8ApP35kT2vd-3Sn1>. Acesso em 20 de abril de 2019. FERREIRA, Manuel. 0 círculo do Mar e o «terra-longismo» em «Chiquinho» de Baltasar Lopes. Revista Colóquio/Letras. Notas e Comentários. Lisboa n.ํㅜ 5, Jan. 1972, p. 66-70. 
FERREIRA, Manuel. Literaturas africanas de expressão portuguesa. Venda Nova Amadora: Livraria Bertrand, 1977.

FIGUEIRA, Tchalé. A viagem. Mindelo: Edição do Autor, 2012.

FONSECA, Jorge Carlos. O albergue espanhol. Lisboa: Rosa de Porcelana, 2017.

FONSECA, Mário. Se a luz é para todos. Praia: Publicom, 1998.

FORTES, Corsino. A cabeça calva de Deus (Pão \& fonema; Árvore \& tambor; Pedras de sol \& substância). Lisboa: Publicações Dom Quixote, 2001.

FORTES, Corsino. Sinos de silêncio. Lisboa: Rosa de Porcelana, 2016.

GADAMER, Hans-Georg. Verdade e método: traços fundamentais de uma hermenêutica. Trad. Flavio Paulo Meurer. São Paulo: São Francisco/Vozes, 2005, p. 156-157.

GLISSANT, Édouard. Solitaire et solidaire, entretien avec Édouard Glissant. In: Pour une littérature-monde. Paris: Gallimard, 2007, p. 78-86.

GNISCI, Armando et alii. La letteratura del mondo nel XXI secolo. Milano: Bruno Mondadori, 2010.

GOMES, Simone Caputo. Arménio Vieira: aulas magnas de arte poética. In: Mulemba. Rio de Janeiro, v. 1, n. 4, p. 44-55, jul. 2011. Disponível em:

< https://revistas.ufrj.br/index.php/mulemba/article/view/4865> . Acesso em 10 de abril de 2019. 
GOMES, Simone Caputo. Impactos e afinidades do conceito de "ambiente" em textos literários cabo-verdianos e brasileiros: uma reflexão sobre a literatura na relação com a experiência traumática. In: GOMES, Simone Caputo e PEREIRA, Érica Antunes (org). Via Atlântica. São Paulo: Departamento de Letras Clássicas e Vernáculas da Universidade de São Paulo, n. 22, dezembro de 2012, p. 139-156.

GOMES, Simone Caputo; PEREIRA, Érica Antunes. Entrevista com Filinto Elísio. Contracorrente: Revista de Estudos Literários e da Cultura, Manaus: UEA, n. 7, p. 220-227, maio 2017. Disponível em: <http:// periodicos.uea.edu.br/index.php/contracorrente/ article/view/571>. Acesso em 13 de abril de 2019. GUMBRECHT, Hans Ulrich. Minimizar identidades. In: JOBIM, José Luís (Org.). Literatura e identidades. Rio de Janeiro: UERJ, 1999, p. 115-124. HORTA, José da Silva. O “nosso' Guiné”: representações luso-africanas do espaço guineense (sécs. XVI-XVII). In: AAVV. Actas do Congresso Internacional "Espaço Atlântico de Antigo Regime: poderes e sociedades". Lisboa: Universidade Nova de Lisboa, 2005, p. 1-14.

LONGXI, Zhang. Epilogue: The Changing Concept of World Literature. In: DAMROSCH, David. World Literature in theory. Chichester: Wiley Blackwell, 2014, p. 513-523.

LONGXI, Zhang. From Comparison to World Literature. Albany: State University of New York Press, 2015. 
LONGXI, Zhang. Canon and World Literature. Journal of World Literature. University of Hong Kong. Vol. 1, No. 1, 2016, p. 119-127.

LONGXI, Zhang. Aspects of word literature. In: Letteratura e letterature, Pisa-Roma: Fabrizio Serra Editore, 11, 2017, p. 59-69.

MABANCKOU, Alain. Le chant de l'oiseau migrateur. In: Pour une littérature-monde. Paris: Gallimard, 2007, p. 54-66.

MALLO, Augustín Fernández. Postpoesía: hacia un nuevo paradigma. Barcelona: Anagrama, 2009.

MORETTI, Franco. Conjeturas sobre a Literatura Mundial. Novos Estudos CEBRAP, 58, novembro de 2000, p. 173-181.

MOTA, Teixeira da. Dois escritores quinhentistas de Cabo Verde: André Álvares de Almada e André Dornelas. Lisboa: Junta de Investigações do Ultramar, 1971. NUNES, António. Poemas de longe. Praia: Instituto Cabo-verdiano do Livro, 1988.

OSÓRIO, Oswaldo. A sexagésima curvatura. Praia: Dada, 2007.

SPIVAK, Gayatri C. Death of a discipline. New York: Columbia University Press, 2003.

TOLENTINO, Luis. Terra gritante. Praia: Grafedito, s/d. VIEIRA, Arménio. O poema, a viagem, o sonho. Lisboa: Editorial Caminho, 2009.

VIEIRA, Arménio. Derivações do Brumário, Lisboa: Rosa de Porcelana, 2013. 
VIEIRA, Arménio. Entrevista ao programa Sempre Ligados, Lisboa, RTP, 28/10/2014. Disponível em:<https://www.youtube.com/watch?time_continue=1\&v=jlJ-24eLp_g>. Acesso em 20 de abril de 2019.

VIEIRA, Arménio. Silvenius: antologia poética. Lisboa: Rosa de Porcelana, 2016. 